\title{
TRASCENDENCIA DEL RAMBAM PARA EL JUDAÍSMO POLACO ${ }^{1}$
}

Transcendence of the Rambam for Polish Judaism

\author{
Benzion Hachmann Wurmberg ${ }^{2}$ \\ Centro de Estudios Judaicos \\ Universidad de Chile
}

En la víspera del estallido de la $2^{\mathrm{a}}$ Guerra Mundial, cuando señales estremecedoras anunciaban la cercanía de la aniquilación, la Kehíla de Varsovia, -la más grande del judaísmo polaco-, galardonó al Rabino Menajem Zemba, entonces miembro del Rabinato de Varsovia.

Esta distinción le fue otorgada por su autoría de la excepcional obra filosófica, referente a Maimónides, presentada en manuscrito.

Aún en los años de la ocupación nazi, en la congoja y las penurias del Gheto de Varsovia según informaciones recibidas por sobrevivientes-el Rabino Zemba no se separó de los escritos del Rambam, y continuó agregando a ellos sus comentarios y observaciones.

En el último Séder celebrado por él, junto a su nieto en los días de Pésaj -antes de haber sucumbido - él relacionó la experiencia estremecedora del judaísmo polaco a las enseñanzas del Rambam ${ }^{3}$ y lo hizo mientras masas de judíos caminaban su última marcha hacia los campos de exterminio de Auschwitz, Treblinka, Haidanek o Sobibor, murmurando el "Ani Maamin", (yo creo) que fue inspirado en los trece principios de fe que,

\footnotetext{
${ }^{1}$ Publicado en Cuadernos Judaicos $N^{\circ} \quad$ (1994)

${ }^{2}$ Benzion Nachman se desempeñ+o como Profesor de Literatura Yidish en el Centro de Estudios Judaicos.

3 En hebreo es común la utilización de siglas que se forman a partir de las primeras letras de los nombres, en este caso se trata de las letras que conforman el nombre de Rabí Mosé ben Maimón (Maimónides), RaMBaM las que se unen con vocales para facilitar su pronunciación.
} 
acorde al Rambam, son parte de la esencia del judaísmo.

Aún en la hora de la aniquilación del judaísmo polaco, el rabino Zemba llevaba consigo, en su corazón, al Rambam y en su palabra buscaba apoyo y consuelo. Los eruditos que se han incorporado en el judaísmo polaco, durante los siglos de su historia, entraron de lleno en su 'espiritualidad, su alma y su siquis, llegando a ser parte de la realidad y visión judeo-polaca del Rambam.

Mientras el Rambam vivía y creaba sus grandiosas obras -y el judaísmo de España ya había vivido su Época de Oro - el judaísmo polaco se encontraba todavía en el inicio de su desarrollo. Apenas entonces en el siglo XII, empezó la inmigración a Polonia de los refugiados de Alemania y de los estados aledaños.

Debido a los cruzados y a la trágica época de matanza y persecuciones, que tuvieron que soportar los judíos en los países occidentales, los caminos estuvieron atestados de desamparados judlos que buscaban desesperados una planicie que les ofreciera un poco de alivio. Entonces, en una de las noches, -según la leyenda-, cayó del Cielo un enigmático papelillo que llevaba la inscripción. "Po-lin" que fue interpretado como que, aquí, en el territorio eslavo podrían pernoctar los judíos mientras dure la oscura noche del Galut, "Polin", Polonia.

Los primeros tiempos fueron difíciles para los inmigrantes y demoró mucho hasta que fuera posible que se enraizarán en la nueva tierra. Crónicas del siglo XIII cuentan de aquellos dolores de parto. Rabi Eliezer de Praga, que en aquel entonces atravesó las regiones eslavas, transmitió detalles de aquellos esfuerzos que el naciente yishuv tuvo que soportar para conservar los refugiados de Alemania, Bohemia y Moravia fundaron las primeras "yeshivot" en Polonia.

La "peste negra" y las calumnias rituales, fueron el fardo pesado que, desde los países

${ }^{4}$ N. del Editor: Yeshivot, del hebr Yeshivá, sing. Academia de estudios rabínicos. 
occidentales de Europa, acompañó a los refugiados; las expulsiones que amenazaron en el occidente a cada Kehilá ${ }^{5}$, aumentó en una medida creciente, el flujo de la inmigración judía. A fines del siglo XV se vigorizaba la espiritualidad judía en diferentes ciudades polacas:, Rabi Moshé Minz en Poznan, Rabi Jejiel Luria en Brest Lotovski, Rabi Levi Kukinich en Lemberg, hacen lo que hicieron generaciones pasadas en otras localidades, ellos labraron la tierra virgen con el pensamiento judaico, ellos porfiadamente sostuvieron que el judaísmo podía desarrollarse independientemente de la geografía y del clima. Y en efecto, en el siglo XVI, es decir 300 años después del deceso del Rambam, cuando en Córdoba y Toledo, en Zaragoza y Málaga la vida judía ya no existía y solo sombras de marranos se deslizaban a lo largo de las callejuelas estrechas, justamente entonces, el Rambam revivía en Polonia en toda su magnitud y vigor.

De la extraordinariamente rica herencia espiritual que el judaísmo de España había dejado, brillaban todavía otros nombres de hombres y obras' que pudieron ofrecer aliento espiritual para un Kibutz naciente. Este 'alimento pudo nutrir el alma acongojada: La poesía tierna y religioso-nacional de Shlomó Ibn Gbirol pudo revelar las fuentes del fluyente judaísmo, la idealista historiosofía de Rabi Yehuda Halevi pudo extender la claridad de la moral judaica, creada con Rabenu Bejay; y por medio de los comentarios líricos de don Yitzjak Abrabanel se pudo elevar el ansia de la llegada del Mesías. Pero de entre, todos estos que eligieron la imponente construcción de la espiritualidad judáica en España, fue justamente el Rabi Moshé ben Maimón quien resultó ser, para el yishuv polaco, más necesario y más atrayente. El Rambam, unificó en su creatividad la halajá y el pensamiento profundo.

El fue el legislador y el pensador, el recién nacido Kibutz judío estaba esperando una personalidad con estas cualidades. La obra halájica de varios volúmenes del Rambam, titulada "Yad Hajazaka" aportó orden sistemático en la muy compleja tradición talmúdica y proyectó una luz sobre la Ley que tenía que ser decidora en la vida cotidiana,y el yishuv judeo-polaco buscaba en aquel periodo inicial apoyo y orientación en los numerosos problemas que se le presentaban en su camino.

\footnotetext{
${ }^{5}$ N. del Ed. Kehilá significa Comunidad
} 
Justo en aquella época terminó en Safed, Eretz Israel, el Rabi Yosef Caro su Código religioso, el "Shulján Arúj" que conquistó luego el reconocimiento de la Diáspora judía, logrando ser conocido también por el judaísmo polaco. Este "Shulján Aruj" fue admirado por su especial amplitud, por su desafio de abarcar todos los aspectos de la vida, por su determinación de entregar a los hombres judíos una respuesta a todas sus preguntas, que sé les podrían presentar; pero luego resultó que la obra de Rabi Yosef Caro, de toda manera, no podía conformar a los usuarios en todos los detalles. Allí no fue considerado el Minhag (la práctica) que en el concepto popular es considerado también como halajá, vigorosa como la Ley. Allá faltaba comprensión para los logros en el campo del judaísmo por parte de los grandes Rabinos en Alemania y Francia. Cierto: también la obra halájica del Rambam no evidenciaba ser distinta en este sentido; también allí quedó establecido en muchos casos la vigencia de la Ley tal como fue interpretada por los judíos en España, pero no fuera de sus límites (como p.e. Francia y Alemania). Sin embargo, teniendo delante de si ambos Códigos, existía la posibilidad de Comparar la obra Yad Hajazaká, que databa desde hace 300 años, con el "Shulján Aruj", publicado mucho más tarde, entonces fue posible encontrar una solución intermedia que deberla ser correcta y la aceptada por el yishuv judeo-polaco en desarrollo. Entre los dos, (Rabí Yosef Caro y Rabi Moshé ben Maimón), fue posible orientarse mejor en la espesura de la tradición de generaciones pasadas y costumbres de la misma época, empeñandose en encontrar una armonía.

Junto a la versatilidad halájica'"él Rambam adquirió un gran prestigio en el yishuv judeopolaco en pleno desarrollo y un aprecio excepcional para su tan característico intelecto humano.

El Kibutz judeo-polaco, aunque todavía joven, desarrolló la agudez de su pensamiento en forma brillante y ya entonces el judío polaco demostró agilidad mental, quizás porque él llevaba consigo los tratados del Talmud; quizás porque él entendió que solamente por medio de una veloz captación se podría asegurar para sí una posición en el nuevo y extraño mundo de las tribus eslavas desconocidas para él. El logró desarrollar estas cualidades 
mediante la meditación y la investigación a fondo de sus estudios. La línea de la dialéctica en el estudio, desarrollada por los "gaonim" talmúdicos en Polonia, Rabi Yaacov Pollak y Rabi Shalom Schachne, fortalecieron la inclinación de sobreponer una interrogante sobre otra y así pulir la mente. Naturalmente la dialéctica escolástica estaba lejos de haber sido clara lógica del Rambam, pero el atrevimiento que es propio para los dos sistemas del pensamiento expresaba la' inquietud espiritual en el yishuv judeo-polaco. Por muy joven que haya sido el Kibutz judío en Polonia, ya entonces pudieron los judíos polacos dirigir a sus líderes preguntas que desde épocas pasadas han atormentado tanto al hombre en general como al judío en especial: ¿qué es la creación?, ¿qué es el universo?, ¿cómo se creó el mundo?, ¿cuáles son los caminos en que el Creador guía y acompaña a lo más selecto de las criaturas, el hombre?, ¿se excluyen mutuamente la fe y el saber?, ¿la fe y el interrogante, o quizás la pregunta está enraizada en la fe auténtica?, ¿qué es lo que sostiene la filosofía o la tradición judía refe-rente a esta problemática tan martirizante? y ¿llega ella, la filosofía, a juntarse con el pensamiento judaico o se esté alejando de él?

¡Qué curioso! no solamente en víspera de los años del Holocausto el Kibutz judío refinado, ramificado atormentado, dolorido en Polonia se han presentado ,estas estremecedoras interrogantes referente a Dios y el Universo, hombre y judío, ser o no ser. No solamente frente a la luz de las llamas temibles en los ghettos, almas martirizadas han formulado sus; interrogantes temblorosas, referente al mundo y a su creación. Ya en el periodo de la formación del yishuv, que apenas estaba dando sus primeros pasos de madurez, se han sacudido a sí mismo y a otros con el atrevimiento de sus interrogantes y la perplejidad. Y es justamente esta circunstancia, este parentesco de almas de una profunda inquietud intelectual la que colocó el Rambam no solamente en el estante de las obras filosóficas del judío-polaco sino, también en su mente y en su corazón.

Estudiaron el Rambam, profundizaron no solamente en sus logros halájicos sino también en sus reflexiones filosóficas; en los debates apasionados muchos lo alabaron y otros lo criticaron; mientras él vivió la polémica en torno a su obra fue viva y después de su deceso se siguió discutiendo no solamente en la Europa Oriental, sino también en la Europa 
Occidental, especialmente sobre su obra "La guía de los perplejos".

En el centro de la polémica estuvo - bajo otros cielos y en otros países- esta, gran obra filosófica del Rambam. Esta, su creación, nacida en medio de la civilización musulmana floreciente, estuvo dedicada a una juventud judía altamente intelectual, porque este libro estaba destinado para uno de estos jóvenes espiritualmente inquietos, dotado con un talento para la investigación y que fue su discípulo, Yosef Acnin, y también para otros que como él se debatían entre la fe y el saber.

Cuando Rabi Moshé Isserlich, más conocido como el "Remi", abrió la obra del Rambam en su residencia de Cracovia, donde dirigía su Yeshivá, se dió cuenta que no se sentía capaz de discutir con sus discípulos el contenido de ella, como lo hizo el Rambam 300 años antes, quien empleaba matices sutiles del pensamiento en sus círculos de estudios. No obstante, también en Cracovia en el Siglo XVI fue destacada la obra "La guía de los Perplejos", como merecedora de profundizar en ella ya que podía proporcionar mucha materia de alta sabiduría. No justamente a la halajá y a determinar las leyes religiosas, se estaba dedicando el Remi, el gran legislador del judaísmo polaco, sino también se dedicaba a la filosofía al estilo del Rambam, publicando una obra filosófica que se llama "El estudio de los oficios religiosos relacionados con el ritual de los sacrificios en el Templo". La intención de esta obra fue la de demostrar que todo problema filosófico puede ser explicado mediante el método de la razón. La razón fue para el legislador de Cracovia igual como lo fue para el legislador de Córdoba, la llama luminosa que debe llevar a los estudiosos a investigar, a buscar, a preguntar y reflexionar incansablemente para encontrar la verdad.

¡Quién no ha gozado de esta emoción, -escribió' el "Remi"-, que uno siente cuando se logra una respuesta a un tema muy complejo, aquel significa tal gozo que no lo ha experimentado no sabe qué significa tal gozo y tal alegría. La finalidad de nuestra existencia es compenetrarnos de la verdad mediante nuestro razonamiento, llegando a perfeccionarse en encontrar la luz, incluso en fenómenos que son sobrenaturales. 
La extraordinaria veneración de la razón humana y de su poder de penetrar en los misterios del cosmos, no impulsa al agudo estudioso Rabino de Cracovia para evitar el estudio de la Torá a través de la Cábala, todo lo contrario hay que otorgarle importancia a la mística en la filosofía de la razón.

Si uno se empeña, observa, el Remi, se puede encontrar parecidas ideas en la "Gula de los Perplejos', como también.en el "Zohar" llegando siempre a las mismas conclusiones. De la misma manera como 'en la investigación del Rambam, sigue porfiada la élite espiritual de aquella época del judaísmo polaco, de tratar de descifrar el enigma, acerca de si el mundo existía, la desde inmemorables épocas o si fue renovado mediante la creación divina. De la misma manera como en la obra descriptiva del Rambam, se estaba debatiendo en aquella época referente a la tesis del filósofo griego de la antigüedad, Aristóteles, comparando con lo que está dicho en la primera frase del Génesis. Aunque no se acepte todo, como el Rambam lo está afirmando, y no obstante, era grande la distancia entre Córdoba y Cracovia, entre Fostat y Lublin, entre el ambiente refinado musulmán y la realidad polaca primitiva, a aquella generación del judaísmo polaco le quedó claro que el Rabino Hoshé ben Maimón era el gran buscador de la verdad, el gran Águila que vuela ti las más excelsas alturas. El pensador de Córdoba revivió en la tierra de Polonia, donde revivió también, la Polémica en toda su aguda fuerza. El congénere del "Rami" y no menos famoso y reconocido como el Rabí Shlomo Luria llamó a dedicar toda la intensidad de su raciocinio en este problema que se presentó ante el yishuv naciente. El Rabi Luria consideró, en general, que dedicarse al pensamiento filosófico era un grave error y le escribió al Remi: "como un cuchillo en la carne viva sentía yo el dolor de tus palabras, tú te has rodeado de sabiduría intrascendente... el gentil Aristóteles es recordado permanentemente por ti, pero la verdadera sabiduría nuestra, la Torá, está envuelta en tristeza, ella está apenada porque sus hijos la están abandonando. Mientras yo veo cómo tú sigues investigando lo que sostiene Aristóteles, yo exclamé, ¡ay de mí, lo que mis ojos ven y lo que mis oídos perciben! Rabi Shlomo Luria sentía más cercano a su corazón la pureza de la fe nuestra, esa fe que no se brinda en especulaciones filosóficas. Rashi ${ }^{6}$ con sus sencillos comentarios es

${ }^{6}$ Rashi abreviatura usual de Rabi Shlomo ben Yitzjak, el más ilustre y popular de los comentaristas de la 
para él la columna del mundo, la columna del judaísmo. El nieto de Rashi, rabenu Yaacov Tam, que participó -durante la época de los cruzados en Alemania- en la redacción de comentarios al Talmud, las Tosafot, se desenvolvió como el más grande comentarista de ésta índole y fue para Rabi Shlomo Luria, el Maestro, cuyos pasos se deberían seguir porque él no permitió que un contenido ajeno sirviera para la construcción de un nido,en el alma judía.

Pero tampoco la autoridad de Rabí Shlomó Luria pudo o logró poner término a esta polémica.

"Es posible pasearse en el jardín de la filosofía" ha escrito Rabí Mordejai Yafe, conocido de acuerdo al título global de sus obras, "Ball Lebushim", afirmando que es posible "juntar o sintetizar la razón con el misterio y borrar las contradicciones que aparentemente son incoherentes. Rabí Mordejai Yafe es el autor de un comentario a la "Guía de los Perplejos". Esta obra tiene mucho que decir y enseñar en todas las épocas y ningún Kibutz judío puede prescindir de ella.

Dice Rabi Shmuel Eidilsh (el Maharashá) que "Cada uno está obligado, con su raciocinio, a llegar: al fondo de los mandamientos religiosos que nosotros cumplimos, porque no puede uno conformarse solamente con la fe; hay que saber y entender y por ello investigación en necesaria".

Una opinión totalmente' distinta expresa Rabí Yoel Sirkis, "el Baj”. El señala que los que se dejan arrastrar a la filosofía se extravían en caminos extraños. La fuente del judaísmo es el misterio. Lo equivocado aunque seductor dejarnos llevar por el convencimiento de que, con la razón, se puede llegar hacia lo que no entendemos.

"Incluso los opositores no aceptaron ciertamente en aquella época las medidas drásticas que Biblia y del Talmud 
se tomaron en Montpellier y París contra la obra investigadora del Rambam hace 300 años atrás. En la Sinagoga de Poznan, al enterarse de lo que pasó exclamó el rabino que se está preparando una nueva edición de la "Guía de los Perplejos", y que constituye una pena el tener que reeditar esta obra. Este hecho excitó los ánimos, y desencadenó una lucha de palabras. El pensador de Córdoba encontró fieles defensores entre el judaísmo polaco.

El Rabí Abraham Horowitz, autor del comentario a los ocho tratados del Rambam, no ahorró expresiones duras en el panfleto que editó en aquella ocasión. "Como los murciélagos - escribía - que no soportan los rayos luminosos del sol, así no pueden Uds. tontos ciegos, soportar la luz de la sabiduría del Rambam; Uds. tienen el atrevimiento de declarar al "Guía de los Descarriados" como un libro de pura superchería y herejía. Pero este libro es un guía fiel que cura todas las heridas espirituales y nos salva de las dudas espirituales, nos levanta hacia el nivel de verdadera perfección ... ¿cómo se atreven Uds. a considerar esta obra como dañina? ¿cómo se atreven Uds. a enfrentarse con el Gaón ${ }^{7}$ de Israel, el hombre divino Rabenu Moshé Ben Maimón?

Generaciones van y generaciones vienen en la historia del judaísmo polaco, este Kibutz judío establecido en tierra eslava que pasa por distintos cambios, políticos sociales, económicos, que viven épocas de alegría y épocas de sufrimiento. Ya florece allá la Kehilá autónoma en la corporación del Judío de las 4 provincias, el consejo de las cuatro regiones como nunca antes habían florecido en la Diáspora judía. Ya parece que se ve que la espada de la aniquilación se levanta contra el yishuv, que ha logrado ascender hacia el liderazgo spiritual en el mundo judío y ya se reconstruye -después de la tragedia de la época de Jimielnitzky y de la congoja de las leyes de 1648 - de nuevo la vida judía sobre las ruinas. Pero la tormenta alrededor de la polémica figura del Rambam y de su creatividad, sigue sin cesar.

El enfrentamiento de las partes prosigue a pesar de que se halla abierta la página de la espiritualidad judía en Polonia. Se aferran a la obra halájica del Rambam; se agregan

\footnotetext{
${ }^{7}$ Gaón, sabio.
} 
nuevos comentarios y opiniones referente a sus logros en la complicada legislatura; pero de ninguna manera pueden llegar a un acuerdo referente a su línea filosófica. Y no todos están seguros si con él es posible llegar a la cumbre del humanismo elevado y del judaísmo además de abrir de par en par las puertas del raciocinio y quitar el velo del misterio.

Observando en profundidad se llega a tener la impresión que la polémica en torno al Rambam, - que se extendió a lo largo de generaciones en el judaísmo polaco - es, en esencia, la polémica consigo mismo. Este es el conflicto entre la razón Y.el sentimiento, entre el intelecto y la emoción, entre la corriente romántica y la línea del positivismo en el cual el judaísmo polaco se encontraba continuamente ya que a fin de cuentas la breve novela entre dos gigantescas montañas de F. L. Péretz y el diálogo que se desenvuelve allá la convierte en más que una novela y más que una sencilla conversación porque allí se enfrentan dos líneas ideológIcas. Allí están, frente a frente, polemizando respecto a un sistema. Y de desprende de ella el enfrentamiento espiritual que en la Polonia judía tomó Incluso una dimensión distinta que la de la España judía en la época del Rambam. No solamente indIviduos participaron en esta controversia sino una colectividad, un Kibutz, un pueblo. Hubo que tomar en cuenta que con el advenimiento del iluminismo en la sociedad judaíca de Europa Oriental y a la vez con el crecimiento del movimiento jasídico, ésta disputa de largo aliento entorno al Rambam, adquirió un nuevo impulso. Pero en este contexto es erróneo pensar que allí se formaron determinados grupos de ideas y que todos los adeptos tanto del iluminismo como del jasidismo iban a reaccionar de la misma manera.

Hubo entre los iluministas adeptos entusiastas al enfoque del Rambam referente a Dios y al hombre, sin embargo, hablan también entre ellos opositores muy tenaces, de la misma manera como en el mundo del jasidismo el Rambam fue considerado como muy identificado con la enseñanza jasídica de la Torá y de la ideología del movimiento jasídico. Mientras otros lo vieron como muy alejado de la esencia del jasidismo.

"El es nuestro guía que ilumina la ignorancia nuestra" -escribió el investigador y el erudito iluminista Shlomo Yehuda Rapaport - refiriéndose al Rambam ... "el instruye a uno de sus 
discípulos en sus obras: tú debes profundizar y tus ojos se iluminarán y en sus palabras tu reconocerás una luz muy brillante.

Najman Krochmal, el pensador destacado de la época preiluminista, opina que para el Rambam no rige el envejecimiento, porque está permanentemente vigente. ¿Acaso no se encuentra ahora, como en la generación del Rambam la juventud judía en la encrucijada? ¿Acaso no está ella, como en la época del Rambam muy desorientada, buscando en sus extravíos a un guía?. Ya el nombre de la obra que Najman Krochmal escribió demuestra cuán fuerte fue la influencia del Rambam sobre él: "La Guía de los Perplejos contemporáneos".

Se entiende que aquí hay espacio también para nuevas y modernas teorías filosóficas, acá no se trata tanto de la filosofía de Aristóteles, sino en torno a Kant y Hegel; acá se oye el eco de la época moderna del Siglo XIX, sus revoluciones y trastornos, su prosa y su poesía; aquí se topan con una terminología moderna con el "espíritu de la. época". Pero también en el panorama, material y espiritual cambiante, sigue siendo el Rambam la figura central que Najman Krochmal presenta a sus discípulos, a los que explica en qué consiste su propia línea. Casi lo mismo ocurre en Lituania, donde el joven erudito Shlomo Maimon, originario de la parte polaca de Lituania-, conquista para sí mismo el reconocimiento de la filosofía europea.

Cuenta Sholomo Maimon: "mi veneración para el Rambam, este gran maestro fue tan fuerte que yo lo consideraba como el supremo ideal del hombre, el más perfecto de los perfectos. El es el grande, quizás el más grande de nuestro pueblo una obra como la "Guía de los Perplejos" jamás fue escrita antes de la aparición del Rambam y tampoco después de su desaparición".

La obra escrita por Shlomo Maimón quedó sin terminar por razones no especificadas.

Pero, en los mismos círculos iluministas, Yakov Shmuel Bik, vende su ejemplar de la "Guía 
de los Perplejos", aduciendo que no vale la pena poseer una obra así porque en ella se desarrollan tesis dañinas ... también en Trieste, que en ese entonces estuvo bajo el dominio austriaco y por lo tanto podían entrar las corrientes espirituales de las regiones judías de Europa oriental, ocurre que Shmuel David Luzatto, lanza una serie de argumentos llamando a la juventud judía a alejarse del Rambam y de su obra: El Rambam, -argumenta S. D. Luzatto-, por ende sus seguidores querían introducir la filosofía en el campo de la religión; al parecer ellos no sabían o no entendían que estas disciplinas representan mundos diferentes. "La filosofía busca la verdad en cambio la religión busca lo bueno y lo justo y el hombre no es enteramente racional él es también poesía y la poesía es la sustancia fundamental del hombre, su vida y su alma": Al igual corno en la época anterior Rabi Shlomo Luria se oponía al Rambam y a sus tesis filosóficas. También lo hace S. D. Luzatto, teniendo ambos corno argumento la sencillez del Rashi y su fe pura y emotiva.

En lo referente al jasidismo también acá, por muy curioso que parezca, el maestro de la halajá y pensador de Córdoba, fue incorporado al tejido de la realidad jasídica y a la vez de la leyenda jasidica. ¿Acaso Rabi Moshé ben Maimón y Rabi Israel Baal Shem Tov tenían un idioma común y se había construido entre ellos una unión armoniosa no solamente en lo que se refiere a expresar un veredicto, sino también en referente al pensamiento filosófico? La leyenda jasidica lo pudo armonizar en forma respetuosa al médico de cabecera del Sultán y al excavador de la greda a la cual se dedicaba el Baal Shem Tov. Los dos se entendieron muy bien en el mundo espiritual donde sus almas se encontraron. Pero el nieto del Baal Shem Tov, rabi Najmann de Brazlaw no se sintió muy cómodo con los pensamientos del Rambam; a él le parecieron demasiado extraños y fríos y él dudaba si con ellos se podía escuchar la melodía que Rabi Haj-mann anhelaba escuchar. Pero no todos en el jasidismo estuvieron de acuerdo con la crítica de Brazlaw. Rabi Schneuer Zalman de Liadi exclamó con admiración: ¿Quién es más grande que el Rambam? Ya estando el Rambam todavía en vida, los judíos del Yemen colocaron su nombre en el Kadish porque ellos sintieron su grandeza.

El Rabí Menajem Mendl de Vitebsk, sostuvo que nosotros en nuestra bajeza no somos 
capaces de concebir la profundidad de las palabras del Rambam. Rabí Pinjas de Koretz no permitió que sacaran el Moré Nevujim de su armario. "Todos los libros del Rambam -dijo él-, incluso el Moré Nevujim, fortalecen la fe del judío y le proporciona una veneración a Dios".

Cada noche antes de acostarse el Rabí de Sandz Rabi Jaim Halberstamm, solía murmurar la siguiente oración: "Creador del mundo ayúdame a servirte igual como te sirvió el Rambam". El Rabí Jalm de Sandz solía estudiar el "More Nevujim" en la noche de Yom Kipur después de Kol Nidré y mientras la masa de los jasidim estaban mojando con sus lágrimas el libro de Tehilim o el Zohar, él con su devoción y entusiasmo elevaba en el Día Sagrado las palabras el Rambam a su más alto nivel.

El Gaón de Vilna, como es sabido, no estaba de acuerdo con todo, lo que Rabi Shneur Zalman ha dicho y hecho. El Gaón opositor del jasidismo junto al Zadik jasídico, no compartió muchas ideas del rabí jasídico, pero en lo referente al Rambam no hubo discordancias. El Gaón de Vilna consideraba que el Rambam debía ser estudiado intensamente y había que compenetrarse de sus ideas y pensamientos.

El jasidismo que se desarrolló en Polonia, este jasidismo estricto e incansablemente esforzado, buscaba en el Rambam. un sustento. El rabí Bunem de Pshisje, cuando todavía era farmacéutico, no se separaba nunca de la obra del Rambam. ¿Y qué obras se encontraban sobre la mesa de Rabi Mendele de Kotzk en sus años de retiro espiritual, encerrado en su pieza y solamente en muy raras ocasiones aparecía entre sus adeptos? Tal como se cuenta este. Rabi seguía estudiando permanentemente el "Guia de los Perplejos". En las ciudades y villorrios de Polonia y Lituania, en la víspera del Holocausto fue Maimónides una figura muy íntima para muchos judíos y sus obras seguían siendo una fuente de la cual se sacaba incansablemente inspiración. Quien justamente deseaba admirar la claridad y la permeabilidad de la Ley, tal como ella fue analizada y expresada por el Rambam en los 14 capítulos de su "Yad Hajazaká; quien estaba buscando consuelo y esperanza en las cartas, que el Rambam en su tiempo mandaba a las Comunidades de 
Marruecos y Yemen, oprimidos y perseguidos en forma muy parecida a la situación en la cual los judíos vivieron al borde del Holocausto; quien intentó despertar y llamar a los judíos también en la época de la desdicha y de la congoja de purificarse en sus modales y conductas y estaba seguro que los capítulos éticos del Rambam correspondian a las necesidades y a la problemática de las distintas generaciones quien se encontraba permanentemente en la duda del problema entre la fe y la comprensión, considerando que las ideas filosóficas del Rambam no deben ser soltadas de la mano, porque ellas conservaron su vigencia e importancia como guías; o aquellos que como Mordejai Zeev Feuerberg, discípulo de la Yeshiva en su estremecedora novela nA donde" buscaba una mano que le través del zigzagueante camino de la vida, guiarlos hacia la meta y el equilibrio.

Nosotros, que hemos vivido en Polonia en víspera del Holocausto, recordamos con piedad y seriedad, una fecha en el Luaj que tuvo que ver con la vida y creación del Rambam: Estudios y lecciones fueron ofrecidos, Obras y ensayos aparecieron; los diarios y revistas dedicaron suplementos especiales en yidish, hebreo y polaco. La conferencia sobre el Rambam de Rabi Moshé Soloweichik, dio lugar para la aparición de nuevos comentarios.

El ensayo de Ajad Haam "El dominio de la razón" sirvió como tema para discusiones. La edición científica de la obra del Rambam. "Sefer Homada", siendo su autor Shimon Ravidovich, se transformó en un material de lectura popular.

El premio que la administración de la Kehila en Varsovia otorgó, en víspera del Holocausto, al Rabino Menajem Zemba -comerciante en fierro en Praga, suburbio de Varsovia, quien fue considerado como el genio más grande de Polonia y fue incorporado como miembro del Comité Judío Ha-rabanim de Varsovia como compensación por su erudita obra sobre el Rambam- adquiere ahora, a raíz de la trágica destrucción del judaísmo polaco, una expresión simbólica.

La distinción Rambam para aquel meritorio genio que perdió su vida en el Ghetto de 
Varsovia, puso término a la existencia del Rambam dentro del marco de las generaciones judías polacas y a la calidez con la cual se estaban relacionando con él los conflictos y debates que fueron temas frecuentes. El pensador de Córdoba, que fue acogido en la colectividad del judaísmo polaco en los inicios de su existencia, ahora, en la angustiosa fase final, desapareció junto al Kibutz inmolado.

Los sonidos del "Ani Haamin", basados en el motivo del Rambam con el cual las masas judías marcharon a las cámaras de gas, conforman una conmovedora comprobación, de que a pesar de que el Rambam solía agregar a la firma de su nombre la frase "Sefardí Tahor" (genuino sefaradí), él también se movla dentro del judaísmo polaco en el decurso de los siglos como un legítimo miembro de Kibutz judío polaco, apenado por las penurias del yishuv judeo-polaco, gozando con sus alegrías, compartiendo sus esperanzas y decepcionado de sus decepciones. El Rambam dijo: judaísmo es pensamiento y el judaísmo polaco pensaba y reflexionaba con la mente y el corazón. 